'Instituto de Neurociencia Biomédica, Facultad de Medicina, Universidad de Chile. Santiago, Chile.

${ }^{2}$ Centro de Gerociencia, Salud Mental y Metabolismo. Santiago, Chile.

${ }^{3}$ Centro de Neurociencia Social y Cognitiva (CSCN), Escuela de Psicología, Universidad Adolfo Ibáñez. Santiago, Chile. aBioquimico. bPhD.

Fuente de apoyo financiero: Financiado por FONDECYT 11160760 (CDA), REDI170583 (CDA), 2018-AARG

591107 (CDA). CONICYTBrazil-441921/2016-7, FONDEFID16110223.

Las autoras declaran no tener conflictos de interés.

Recibido el 13 de noviembre de 2018, aceptado el 27 de diciembre de 2019

Correspondencia a:

Dr. Claudia Duran-Aniotz Centro de Neurociencia Social y Cognitiva (CSCN), Escuela de Psicología, Universidad Adolfo Ibáñez. Santiago, Chile. duran.aniotz@gmail.com

\section{La respuesta a proteínas mal plegadas como blanco terapéutico en la enfermedad de Alzheimer}

\section{CATALINA RIVERA-KRSTULOVIĆ',2,a, CLAUDIA DURAN-ANIOTZZ \\ Unfolded protein response as a target in the treatment of Alzheimer's disease}

The clinical features of Alzheimer's disease $(A D)$, for example the progressive memory loss, are produced by neuronal loss and synaptic dysfunction. These events have been associated with histopathological alterations in $A D$ brain, including the presence of amyloid plaques and neurofibrillary tangles. Recent studies suggest that cellular stress produced by the aggregation of misfolded proteins leads to alterations in protein homeostasis, that is regulated for the most part by endoplasmic reticulum (ER). The ER is the main compartment involved in the folding and secretion of proteins and is drastically affected in $A D$ neurons. Recent evidence implicates the participation of adaptive responses to stress within the ER in the disease process through a signaling pathway known as the Unfolded Protein Response (UPR) which alleviates the protein aggregation and ER stress. Based on the involvement of ER stress in several diseases, efforts are being done to identify small molecules that can inhibit or activate selective UPR components. Here, we review the findings suggesting a functional role of $E R$ stress in the etiology of $A D$. Possible therapeutic strategies to mitigate ER stress in the context of $A D$ are discussed.

(Rev Med Chile 2020; 148: 216-223)

Key words: Alzheimer Disease; Endoplasmic Reticulum Stress; Unfolded Protein Response.
$\mathrm{L}$ a enfermedad de Alzheimer (EA), la forma más común de demencia, pertenece a un grupo de neuropatologías denominado desórdenes de conformación proteica (DCP). Dentro de los DPC se encuentran la enfermedad de Parkinson (EP), la enfermedad de Huntington $(\mathrm{EH})$, la esclerosis lateral amiotrófica (ELA) y las enfermedades producidas por priones ${ }^{1,2}$. Muchas de estas enfermedades están íntimamente asociadas al envejecimiento, por lo que se estima que el número de pacientes afectados por algún DCP aumentará considerablemente en los próximos años ${ }^{1,2}$.

Como parte fundamental de la función biológica, las proteínas deben adquirir un correcto plegamiento y estructura tridimensional. Cuando este plegamiento se realiza de forma anómala debido a situaciones de estrés en el ambiente intra o extracelular, mutaciones u otros eventos, se puede producir la pérdida de las funciones fisiológicas de la proteína, así como la generación de estructuras que resultan tóxicas para la célula, traduciéndose en acontecimientos patológicos ${ }^{1}$. Estos eventos de mal plegamiento resultan en la agregación de proteínas en tejidos específicos y han sido asociados a muchos DPC .

Los agregados proteicos en los DCP poseen la característica de tener una estructura de hoja $\beta$-plegada, estabilizada por interacciones intermoleculares que llevan a la conformación de oligóme- 
ros, protofibrillas y fibrillas que, posteriormente, se acumulan como depósitos amiloides en los tejidos afectados ${ }^{1,2}$. Las proteínas que constituyen los agregados proteicos en los DCP son específicas de cada una de las enfermedades, causando múltiples efectos en diferentes tejidos. De esta forma, el péptido $\beta$-amiloide $(\beta A)$ y la proteína tau están involucrados en la EA; la $\alpha$-sinucleína, en la EP, y la huntingtina, en la $\mathrm{EH}^{1}$. Si tomamos en cuenta estos pronósticos y el hecho de que en este momento no existen métodos diagnósticos o terapéuticos efectivos para estas enfermedades, la investigación biomédica enfocada a entender las bases moleculares de estas condiciones patológicas para la búsqueda de terapias efectivas es de vital importancia.

\section{La enfermedad de Alzheimer}

La enfermedad de Alzheimer es un trastorno neurodegenerativo, progresivo e irreversible, que actualmente afecta aproximadamente a $10 \%$ de las personas mayores a 65 años, y su frecuencia aumenta en $50 \%$ en personas de 85 años o más ${ }^{3}$. Actualmente, en Chile se estima que 179.037 personas sufren de demencia, y entre 50 y $60 \%$ de los casos corresponde a EA ${ }^{4}$. Debido a que la población de edad avanzada está aumentando en la actualidad y que el riesgo a desarrollar EA escala exponencialmente con los años, se predice que su prevalencia mundialmente será el doble para el año $2040^{3}$.

Una de las manifestaciones clínicas de la EA es la pérdida gradual de la memoria, consecuencia de una progresiva disminución de la actividad o función sináptica en el cerebro de los pacientes. Estos eventos están mediados en parte por la deposición de $\beta A$, producto proteolítico de la proteína precursora amiloide (PPA) y la proteína tau hiperfosforilada ( $\mathrm{p}$-tau), la cual está asociada a microtúbulos y forma filamentos helicoides al hiperfosforilarse. Estas estructuras amiloidogénicas provocan la formación de placas seniles y ovillos neurofibrilares, respectivamente ${ }^{3}$. Otras lesiones de EA incluyen pérdida de neuronas, anormalidades sinápticas, estrés oxidativo ${ }^{5}$ y activación de respuestas neuroinmunes anormales ${ }^{6}$.

Como se había mencionado, el envejecimiento es el principal factor de riesgo para desarrollar la EA, puesto que la edad está asociada a un decai- miento gradual de la capacidad amortiguadora de la homeostasis en las células o proteostasis ${ }^{7}$. En este contexto, el desbalance que podría producirse en la red proteostática ha sido ampliamente descrito como un evento temprano en varias patologías y condiciones de neurodegeneración, sugiriéndose un rol causal entre la progresión de la enfermedad y la función proteostática ${ }^{8,9}$.

\section{Respuesta a proteínas mal plegadas}

El retículo endoplasmático (RE) tiene un rol esencial en el proceso de plegamiento de proteínas y ha sido descrito como un componente clave en el restablecimiento de la proteostasis y en la disminución del estrés celular. Un gran número de condiciones pueden provocar alteraciones en la proteostasis, como por ejemplo en la EA, la acumulación continua de $\beta \mathrm{A}$ o p-tau en el RE interfiriere con el funcionamiento normal de este organelo y lleva a una condición celular conocida como estrés de retículo endoplasmático ${ }^{10,11}$. Para aliviar el estrés de RE, las células gatillan una red de eventos de señalización intracelular conocidos como la respuesta a proteínas mal plegadas (del inglés unfolded protein response, [UPR]). La UPR tiene como objetivo el restablecimiento de la homeostasis del RE a través de la disminución de la carga de proteínas mal plegadas en su interior ${ }^{10}$. Este proceso está compuesto por tres sensores proteicos principales: la proteína quinasa PERK (del inglés double-standed RNA-activated protein kinase (PRK) like endoplasmic reticulum kinase), la enzima dependiente de inositol 1 (IRE1) y el factor de transcripción activador (ATF) $6 \alpha$ y $\beta$ $($ Figura 1) 12 .

$\mathrm{Al}$ activarse la vía de PERK, este dimeriza y se autotransfosforila, lo que conlleva a la fosforilación del factor iniciador de transcripción eucariótico $2 \alpha$ (eIF2 $\alpha$ ), el cual produce la detención del proceso de síntesis proteica y alivia así la sobrecarga proteica dentro del $\mathrm{RE}^{13}$. La vía de IRE1 $\alpha$, la cual es la más conservada de estos sensores, cataliza el procesamiento del ARNm que codifica para el factor de transcripción XBP1 ( $X$ box-binding protein 1), resultando en la expresión procesada, madura y activa de XBP1 (spliced XBP1, XBP1s), un potente factor de transcripción que regula un conjunto de blancos de UPR para adaptarse al estrés de $\mathrm{RE}^{14,15}$. 


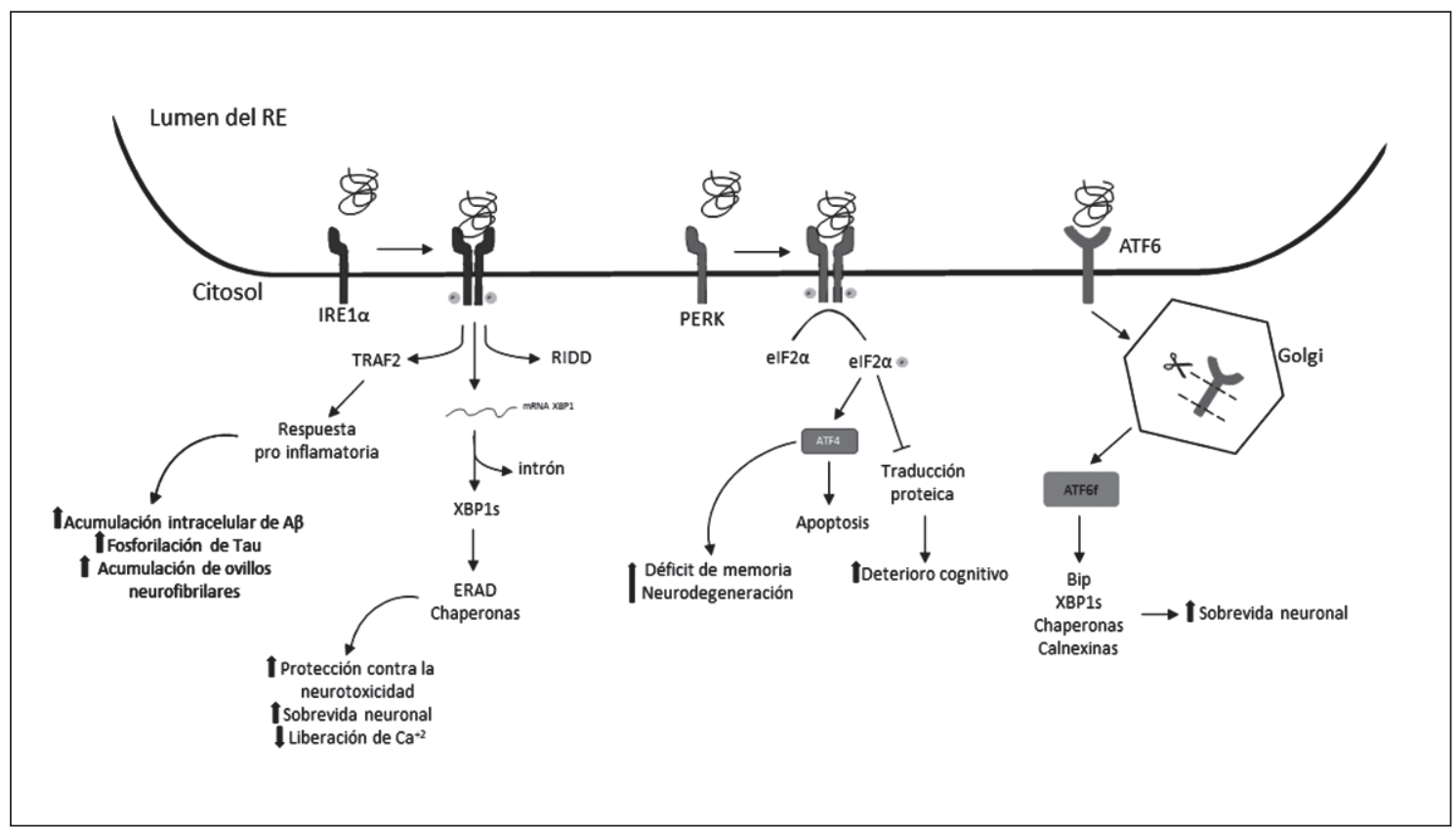

Figura 1. Respuesta a proteínas mal plegadas (UPR) y su rol en la enfermedad de Alzheimer. El estrés de retículo induce una respuesta adaptativa conocida como la UPR. La respuesta de la UPR es controlada por 3 sensores de estrés principales: IRE1, PERK y ATF6. La actividad RNasa de IRE1 procesa el mARN que codifica para el factor de transcripción XBP1, permitiendo la expresión de su forma activa que actúa sobre genes relacionados con la UPR y la sobrevida celular. PERK fosforila elF2? inhibiendo la síntesis de proteínas y aumentando la expresión de ATF4, un factor de transcripción que reprime CREB2, asociado a la consolidación de la memoria. Finalmente, ATF6 es exportado desde el retículo endoplasmatico al aparato de Golgi, en donde sufre una proteólisis, liberando su dominio citosólico (ATF6f) que actúa en genes proadaptativos.

En el caso de la vía de ATF6, bajo condiciones de estrés, la cola citoplasmática de ATF6 es procesada proteolíticamente. Este proceso produce la liberación de un fragmento citosólico activo $(\text { ATF6f })^{13}$ que regula una serie de genes blanco de UPR involucrados en el control de calidad proteico y degradación de proteínas mediante un mecanismo conocido como ERAD (Endoplasmic Reticulum-associated degradation) (Figura 1) ${ }^{13}$.

La activación de la UPR mejora la capacidad basal de la célula de producir proteínas maduras a través de la regulación de la síntesis de proteínas y la de los genes involucrados en los mecanismos de control de calidad del plegamiento proteico, síntesis de lípidos, y la degradación de proteínas mal plegadas ${ }^{16}$, promoviendo así la adaptación de las células al estrés de RE. Si el estrés de RE es irreversible o crónico, la UPR gatilla muerte celular por apoptosis ${ }^{11}$. Así, la activación de la UPR tiene distintas consecuencias en la expresión génica y la fisiología celular, por lo que la modu- lación selectiva de la vía adaptativa o de las vías de señalización se puede utilizar en contextos de enfermedad específicos, ofreciendo nuevos blancos terapéuticos para la intervención de distintas enfermedades.

\section{El impacto de la UPR en la enfermedad de Alzheimer}

La etiología de la EA es aún desconocida, sin embargo, se ha propuesto al estrés de RE como un factor patológico transversal, tanto en la forma familiar como esporádica de la enfermedad ${ }^{17,18}$. La activación de la UPR bajo condiciones de estrés de RE se ha descrito como una de las respuestas transcripcionales principales para restaurar la proteostasis y sustentar la función y sobrevida celular. En condiciones normales, los tres principales sensores de la UPR se encuentran unidos a la proteína de unión (del inglés Binding protein, [BiP]), y al activarse la UPR los sensores son li- 
berados de esta unión ${ }^{11,19}$. Interesantemente, uno de los primeros trabajos en relación a marcadores de estrés de RE en cerebros de pacientes con la EA describió la sobreexpresión de BiP específicamente en hipocampo y corteza entorrinal ${ }^{20}$. En esta misma línea, trabajos posteriores mostraron la activación de diversos marcadores del estrés de RE y, por consiguiente, la UPR en el tejido cerebral post mortem de pacientes de la EA como HSP72 (otra chaperona asociada con placas $\beta$ A y ovillos de p-tau) ${ }^{19}$, endoplasmina (Grp94) y la proteína disulfuro-isomerasa (PDI) ${ }^{17,20-26}$. Más aun, niveles elevados de los marcadores de UPR también se han descrito en neuronas morfológicamente intactas $^{17,24}$, sugiriendo que la UPR parece ser un evento temprano en la neuropatología de la EA.

Por otro lado, también se han encontrado que los niveles de componentes proapoptóticos de la UPR como CHOP/GADD153, el cual está mayoritariamente asociado a la activación de PERK, se encuentran elevados en pacientes con la $\mathrm{EA}^{27}$, posiblemente por consecuencia de un estrés de RE prolongado.

Recientemente, se observó que uno de los sensores de la UPR, IRE1 en su forma fosforilada, está directamente correlacionado con los distintos estadios Braak en cerebros de pacientes con la $\mathrm{EA}^{28}$. Asimismo, en neuronas corticales de pacientes de la EA se observó una correlación positiva entre la presencia de p-tau con marcadores de estrés de $\mathrm{RE}^{17,26} \mathrm{y}$, además, se determinaron alteraciones significativas en el procesamiento del ARNm de XBP1 de pacientes afectados con la $\mathrm{EA}^{29}$. Este factor de trascripción tiene la capacidad de regular los niveles de estrés de RE y tiene un rol neuroprotector, promoviendo la regeneración axonal, reduciendo la acumulación de inclusiones proteicas y mejorando la función sináptica ${ }^{30}$.

Diversos reportes en modelos de cultivo celular de la EA sugieren que el estrés de RE es un mecanismo de muerte celular desencadenado por el péptido $\beta$ A, asociado con la alteración de la homeostasis del calcio en el RE ${ }^{31}$. Además, algunos estudios muestran que los efectos del estrés de RE en la inhibición de la síntesis proteica contribuyen a la disfunción cognitiva observada en los modelos murinos de la $\mathrm{EA}^{32,33}$ (ver detalle en Figura 1).

Interesantemente, mediante un análisis de expresión génica, se identificó que XBP1 controla la expresión de un conjunto de genes relacionados con la EA ${ }^{15}$. Recientemente, se describió que un polimorfismo en el promotor de XBP1 opera como un factor de riesgo para desarrollar la EA en la población Han de $\mathrm{China}^{34}$, demostrando el rol causal de alteraciones de la UPR en la enfermedad. Previamente, este polimorfismo había sido asociado como un factor de riesgo para el desarrollo del desorden bipolar y la esquizofrenia en la población japonesa ${ }^{35-41}$. Asimismo, se ha demostrado que en las regiones corticales de tejido post mortem de cerebros de pacientes con la EA se observa una disminución de los niveles del ARNm de XBP1 ${ }^{42}$.

Recientemente, descubrimos un rol inesperado de IRE1 $\alpha$ en la patogénesis de la EA. Observamos que la remoción genética del dominio ribonucleasa de IRE1 en el sistema nervioso central restauró significativamente la capacidad de memoria y aprendizaje en ratones transgénicos para la EA, además de reducir los niveles de proteínas precursoras de amiloide (PPA) en las áreas corticales e hipocampales en el cerebro de estos $^{28}$. Por otra parte, estudios en modelos de D. melanogaster de la EA han demostrado que la expresión ectópica de XBP1s protege contra la neurotoxicidad del péptido beta amiloide ${ }^{43} \mathrm{y}$ de la proteína tau ${ }^{44}$. Adicionalmente, la sobreexpresión de la forma activa de XBP1 en ratones transgénicos, o a través de la administración a nivel local en el hipocampo, genera un aumento en el rendimiento de los animales en paradigmas de memoria y aprendizaje ${ }^{45}$. Esta nueva función de XBP1 involucra la regulación transcripcional directa del factor neurotrófico derivado del cerebro (BDNF, del inglés brain-derived neurotrophic factor), un factor clave que regula la sinaptogénesis y el desarrollo del cerebro ${ }^{45,46}$. Por otro lado, se demostró que la administración local de XBP1s en modelos murinos transgénicos de la enfermedad reduce el deterioro en los procesos cognitivos asociados a esta patología de manera independiente a la vía de la UPR, activando a nivel transcripcional a kalirina-7, una proteína importante en la formación de la sinapsis y en los procesos de plasticidad sináptica ${ }^{47,48}$.

\section{La UPR como blanco para intervención terapéutica}

La modulación de la UPR mediante estrategias terapéuticas dirigidas a reducir el estrés de RE y aumentar la capacidad proteostática de las neuro- 
nas se encuentra actualmente en desarrollo debido a su gran potencial biotecnológico ${ }^{49}$.

En relación a la rama de PERK, la mayoría de los compuestos disponibles, como salubrinal, no apuntan a PERK en sí, sino al nivel de fosforilación de eIF $2 \alpha$, a través de la inhibición de sus complejos fosfatasa, manteniendo el bloqueo de la traducción de proteínas ${ }^{50}$. Interesantemente, tres quinasas de eIF2 $\alpha$ han sido relacionadas con alteraciones de la sinapsis y déficit cognitivo en modelos murinos de la $\mathrm{EA}^{33}$. Otros inhibidores de eIF $2 \alpha$ estudiados son sephin 1 y guamabenz, los cuales han sido testeados en varios modelos de neurodegeneración, mostrando un gran potencial neuroprotectivo ${ }^{51}$. ISRIB (Integrated Stress Response Inhibitor), otro inhibidor de eIF2 $\alpha$, también ha mostrado que mejora el aprendizaje y la memoria en ratas ${ }^{52}$. Además, este potente inhibidor presenta propiedades farmacocinéticas prometedoras, ya que cruza la barrera hematoencefálica sin efectos adversos en el animal, sin embargo, al administrar ISRIB a un modelo murino de EA no se observó modificación de la patogénesis de la enfermedad ${ }^{53}$.

Se ha estudiado extensamente el rol terapéutico de XBP1 en distintas neuropatologías, por ejemplo en la EP, la entrega local de XBP1s en la sustancia negra en un modelo de la enfermedad resultó en una disminución de la denervación del estriado y en un aumento en la viabilidad de neuronas dopaminérgicas ${ }^{54}$. En la enfermedad de Huntington, la entrega de la forma activa de XBP1 en el estriado del cerebro de ratones adultos de un modelo de la enfermedad redujo significativamente el número de inclusiones de la proteína huntingtina en comparación a los animales control ${ }^{55}$. En cuanto al papel de XBP1s en la neuroprotección, se estudió el efecto de la entrega local de XBP1s de manera selectiva en neuronas de animales adultos en condiciones de daño axonal, obteniendo un aumento en el número de axones regenerados en los animales expuestos a XBP1s, sugiriendo que su expresión podría promover la regeneración axonal luego de una lesión en el nervio periférico ${ }^{56}$.

Por otro lado, se han utilizado como blanco terapéutico las chaperonas químicas, que son pequeñas moléculas que estabilizan proteínas, teniendo un posible potencial farmacológico debido a que reducen los niveles de estrés de retículo significativamente ${ }^{57}$. Actualmente, tres principales chaperonas químicas han sido estudiadas extensivamente y están aprobadas por la agencia estadounidense de administración de alimentos y medicamentos, y estas son ácido 4-fenilbutírico, trehalosa y ácido tauroursodeoxicólico. En este contexto, tanto en modelos celulares como en modelos animales, estas chaperonas muestran un efecto protector contra el estrés de RE en distintas enfermedades ${ }^{57}$. Por ejemplo, el ácido 4-fenilbutírico mejora la disminución cognitiva en ratones transgénicos para la proteína $\operatorname{tau}^{58}$, la administración del ácido tauroursodeoxicólico reduce la deposición amiloide en ratones con EA y mejora su capacidad cognitiva ${ }^{59} \mathrm{y}$, finalmente, la trehalosa ha mostrado protección contra el deterioro en la capacidad cognitiva y de aprendizaje propio de la patogénesis de la EA, además, de disminuir la deposición de $\beta A$ en el hipocampo ${ }^{60}$. A pesar de que las chaperonas químicas necesitan una mayor caracterización en los modelos de la $\mathrm{EA}$, constituyen una posible vía para un futuro desarrollo terapéutico.

Recientemente, se están desarrollando nuevos métodos terapéuticos para restaurar la proteostasis, aumentando artificialmente los programas adaptativos, específicamente entregando factores claves para disminuir el estrés de RE. La terapia génica es una de las estrategias más vanguardistas que podría permitir la corrección de eventos patológicos en forma local, específica y definitiva, reduciendo enormemente los efectos secundarios sistémicos observados cuando se utilizan fármacos de administración prolongada ${ }^{61,62}$. Recientemente, el uso de virus adeno-asociados (AAVs) para terapia génica ha aumentado significativamente luego de la aprobación de dos terapias génicas contra la leucemia y una forma genética de ceguera ${ }^{63,64}$, además de que no se han reportado efectos secundarios en humanos tratados con AAVs ${ }^{65}$. La entrega de genes mediada por AAVs ha surgido como la herramienta más efectiva y segura para estudios preclínicos y clínicos de desórdenes neurológi$\cos ^{66,67}$. Se ha reportado la expresión del transgen por más de 10 años en estudios en monos, lo que demuestra la estabilidad de su expresión, generando una ventaja en la terapia génica al requerir solo una aplicación ${ }^{68}$. Recientemente, un ensayo clínico utilizando terapia génica (AVXS, Avexis-Novartis) para la atrofia muscular espinal en niños, mostró mejorías clínicas significativas, indicando la efectividad y seguridad de los adenovirus ${ }^{69}$. Sin embargo, los estudios que utilizan terapia génica como tratamiento para la EA se encuentran en una 
etapa preclínica, con la excepción de un estudio que utiliza adenovirus para sobreexpresar el factor de crecimiento nervioso, el cual se encuentra en fase I de su ensayo clínico $^{70}$. Las terapias actuales basadas en vectores virales recombinantes buscan alterar la expresión de genes/procesos blancos en el hipocampo o en la corteza mediante la inyección de vectores virales genéticamente modificados. Es por esto que la utilización de esta técnica en la EA es ideal, dado que la zona cerebral afectada en la enfermedad está claramente identificada y delimitada espacialmente.

Adicionalmente, en la actualidad se han desarrollado distintos serotipos virales que permiten un tropismo específico para determinados tipos celulares (es decir, astrocitos, oligodendrocitos, neuronas, etc. ${ }^{71}$ ). Esto, combinado con promotores celular o tejido específico, puede asegurar la expresión controlada y restringida del transgen.

\section{Conclusiones}

La EA es una enfermedad multifactorial donde se sugiere que el funcionamiento anómalo de la proteostasis tiene un rol fundamental en la patogénesis de la enfermedad ${ }^{9}$. A pesar de todo el potencial terapéutico, las estrategias para aliviar el estrés de retículo en modelos murinos han sido pobremente exploradas en la EA ${ }^{72}$. La complejidad de la señalización de la UPR ofrece múltiples niveles de intervención, que van desde los sensores de estrés, moduladores, factores de transcripción, hasta los miles de blancos río abajo de la señalización. En este sentido, la manipulación de los factores que participan en el sistema de respuesta a estrés de RE están, actualmente, captando la atención como posibles objetivos terapéuticos en la generación de tratamientos para EA que permitan, por ejemplo, aumentar el sistema de respuesta a estrés de RE, pudiendo así ser capaz de disminuir las características principales de la patología, entre las cuales se incluye la alteración de los procesos sinápticos, la agregación proteica y el mal plegamiento de proteínas, entre otros.

\section{Referencias}

1. Soto C. Unfolding the role of protein misfolding in neurodegenerative diseases. Nature reviews. Neuroscience 2003; 4(1): 49-60.

2. Duran-Aniotz C, Moreno-Gonzalez I, Morales R.
[Amyloid aggregates: role in Protein Misfolding Disorders]. Rev Med Chile 2013; 141 (4): 495-505.

3. Ballard C1, Gauthier S, Corbett A, Brayne C, Aarsland D, Jones E. Alzheimer's disease. Lancet 2011; 377 (9770): 1019-31.

4. Slachevsky A, Budinich M, Miranda-Castillo C, Núñez-Huasaf J, Silva JR, Muñoz-Neira C, et al. The CUIDEME Study: determinants of burden in Chilean primary caregivers of patients with dementia. J Alzheimers Dis 2013; 35 (2): 297-306.

5. Krstic D, Knuesel I. Deciphering the mechanism underlying late-onset Alzheimer disease. Nat Rev Neurol 2013; 9 (1): 25-34.

6. McGeer PL, McGeer EG. NSAIDs and Alzheimer disease: epidemiological, animal model and clinical studies. Neurobiol Aging 2007; 28 (5): 639-47.

7. Kaushik S, Cuervo AM. Proteostasis and aging. Nat Med 2015; 21 (12): 1406-15.

8. Oakes SA, Papa FR. The Role of Endoplasmic Reticulum Stress in Human Pathology. Annu Rev Pathol 2015; 10: 173-94.

9. Hetz C, Mollereau B. Disturbance of endoplasmic reticulum proteostasis in neurodegenerative diseases. Nat Rev Neurosci 2014; 15 (4): 233-49.

10. Walter P, Ron D. The Unfolded Protein Response: From Stress Pathway to Homeostatic Regulation. Science 2011; 334: 1081-6.

11. Hetz C, Chevet E, Oakes SA. Proteostasis control by the unfolded protein response. Nat Cell Biol 2015; 17 (7): 829-38.

12. Bertolotti A, Zhang Y, Hendershot LM, Harding HP, Ron D. Dynamic interaction of BiP and ER stress transducers in the unfolded-protein response. Nature Cell Biology 2000; 2: 326-32.

13. Hetz C, Saxena S. ER stress and the unfolded protein response in neurodegeneration. Nat Rev Neurol 2017; 13 (8): 477-91.

14. Lee AH, Iwakoshi NN, Glimcher LH. XBP-1 regulates a subset of endoplasmic reticulum resident chaperone genes in the unfolded protein response. Mol Cell Biol 2003; 23 (21): 7448-59.

15. Acosta-Alvear D, Zhou Y, Blais A, Tsikitis M, Lents $\mathrm{NH}$, Arias $\mathrm{C}$, et al. XBP1 controls diverse cell type- and condition-specific transcriptional regulatory networks. Mol Cell 2007; 27 (1): 53-66.

16. Hetz C, Papa FR. The Unfolded Protein Response and Cell Fate Control. Mol Cell 2018; 69 (2): 169-81.

17. Hoozemans JJ, van Haastert ES, Nijholt DA, Rozemuller AJ, Eikelenboom P, Scheper W. The unfolded protein response is activated in pretangle neurons in alzheimer's disease hippocampus. Am J Pathol 2009; 174 (4): 1241-51. 
18. Scheper W, Hoozemans JJ. The unfolded protein response in neurodegenerative diseases: a neuropathological perspective. Acta Neuropathol 2015; 130 (3): 315-31.

19. Santos LE, Ferreira ST. Crosstalk between endoplasmic reticulum stress and brain inflammation in Alzheimer's disease. Neuropharmacology 2018; 136 (Pt B): 350-60.

20. Hamos JE, Oblas B, Pulaski-Salo D, Welch WJ, Bole DG, Drachman DA. Expression of heat shock proteins in Alzheimer's disease. Neurology 1991; 41 (3): 345-50.

21. Scheper W, Hoozemans JJ, Hoogenraad CC, Rozemuller AJ, Eikelenboom P, Baas F. Rab6 is increased in Alzheimer's disease brain and correlates with endoplasmic reticulum stress. Neuropathol Appl Neurobiol 2007; 33 (5): 523-32.

22. Katayama T, Imaizumi K, Manabe T, Hitomi J, Kudo T, Tohyama M. Induction of neuronal death by ER stress in Alzheimer's disease. J Chem Neuroanat 2004; 28 (12): 67-78.

23. Lee JH, Won SM, Suh J, Son SJ, Moon GJ, Park UJ, et al. Induction of the unfolded protein response and cell death pathway in Alzheimer's disease, but not in aged Tg2576 mice. Exp Mol Med 2010; 42 (5): 386-94.

24. Hoozemans JJ, Veerhuis R, Van Haastert ES, Rozemuller JM, Baas F, Eikelenboom P, et al. The unfolded protein response is activated in Alzheimer's disease. Acta Neuropathol 2005; 110 (2): 165-72.

25. Biswas SC, Shi Y, Vonsattel JP, Leung CL, Troy CM, Greene LA. Bim is elevated in Alzheimer's disease neurons and is required for beta-amyloid-induced neuronal apoptosis. J Neurosci 2007; 27 (4): 893-900.

26. Hoozemans JJ, Scheper W. Endoplasmic reticulum: the unfolded protein response is tangled in neurodegeneration. Int J Biochem Cell Biol 2012; 44 (8): 1295-8.

27. Yoon SO, Park DJ, Ryu JC, Ozer HG, Tep C, Shin YJ, et al. JNK3 perpetuates metabolic stress induced by Abeta peptides. Neuron 2012; 75 (5): 824-37.

28. Duran-Aniotz C, Cornejo VH, Espinoza S, Ardiles ÁO, Medinas DB, Salazar C, et al. IRE1 signaling exacerbates Alzheimer's disease pathogenesis. Acta Neuropathol 2017; 134 (3): 489-506.

29. Lee DY, Lee KS, Lee HJ, Kim DH, Noh YH, Yu K, et al. Activation of PERK signaling attenuates Abeta-mediated ER stress. PLoS One 2010; 5 (5): e10489.

30. Valenzuela V, Martínez G, Duran-Aniotz C, Hetz C. Gene therapy to target ER stress in brain diseases. Brain Res 2016; 1648 (Pt B): 561-70.

31. Viana RJ, Nunes AF, Rodrigues CM. Endoplasmic Reticulum Enrollment in Alzheimer's Disease. Mol Neurobiol 2012; 46 (2): 522-34.

32. Ma T, Trinh MA, Wexler AJ, Bourbon C, Gatti E, Pierre $\mathrm{P}$, et al. Suppression of eIF2alpha kinases alleviates Al- zheimer's disease-related plasticity and memory deficits. Nat Neurosci 2013; 16 (9): 1299-305.

33. Duran-Aniotz C, Martínez G, Hetz C. Memory loss in Alzheimer's disease: are the alterations in the UPR network involved in the cognitive impairment? Front Aging Neurosci 2014; 6: 8.

34. Liu SY, Wang W, Cai ZY, Yao LF, Chen ZW, Wang CY, et al. Polymorphism -116C/G of Human X-box-Binding Protein 1 Promoter is Associated with Risk of Alzheimer's Disease. CNS Neurosci Ther 2013; 19 (4): 229-34.

35. Kakiuchi C, Ishiwata M, Umekage T, Tochigi M, Kohda K, Sasaki T, et al. Association of the XBP1-116C/G polymorphism with schizophrenia in the Japanese population. Psychiatry Clin Neurosci 2004; 58 (4): 438-40.

36. Kakiuchi C1, Iwamoto K, Ishiwata M, Bundo M, Kasahara T, Kusumi I, et al. Impaired feedback regulation of $\mathrm{XBP} 1$ as a genetic risk factor for bipolar disorder. Nat Genet 2003; 35 (2): 171-5.

37. Chen W, Duan S, Zhou J, Sun Y, Zheng Y, Gu N, et al. A case-control study provides evidence of association for a functional polymorphism -197C/G in XBP1 to schizophrenia and suggests a sex-dependent effect. Biochem Biophys Res Commun 2004; 319 (3): 866-70.

38. Hou SJ, Yen FC, Cheng CY, Tsai SJ, Hong CJ. X-box binding protein 1 (XBP1) C-116G polymorphisms in bipolar disorders and age of onset. Neurosci Lett 2004; 367 (2): 232-4.

39. Watanabe Y, Fukui N, Muratake T, Amagane H, Kaneko $\mathrm{N}$, Nunokawa A, et al. Association study of a functional promoter polymorphism of the X-box binding protein 1 gene in Japanese patients with schizophrenia. Psychiatry Clin Neurosci 2006; 60 (5): 633-5.

40. Jönsson EG, Cichon S, Schumacher J, Abou Jamra R, Schulze TG, Deschner M, et al. Association study of a functional promoter polymorphism in the XBP1 gene and schizophrenia. Am J Med Genet B Neuropsychiatr Genet 2006; 141B (1): 71-5.

41. Kakiuchi C, Kato T. Lithium response and $-116 \mathrm{C} / \mathrm{G}$ polymorphism of XBP1 in Japanese patients with bipolar disorder. Int J Neuropsychopharmacol 2005; 8 (4): 631-2.

42. Reinhardt S, Schuck F, Grösgen S, Riemenschneider M, Hartmann T, Postina R, et al. Unfolded protein response signaling by transcription factor XBP-1 regulates ADAM10 and is affected in Alzheimer's disease. FASEB J 2014; 28 (2): 978-97.

43. Casas-Tinto S, Zhang Y, Sanchez-Garcia J, Gomez-Velazquez M, Rincon-Limas DE, Fernandez-Funez P. The ER stress factor XBP1s prevents amyloid-beta neurotoxicity. Hum Mol Genet 2011; 20 (11): 2144-60.

44. Loewen CA, Feany MB. The unfolded protein response 
protects from tau neurotoxicity in vivo. PloS one 2010; $5(9)$.

45. Martínez G, Vidal RL, Mardones P, Serrano FG, Ardiles AO, Wirth C, et al. Regulation of Memory Formation by the Transcription Factor XBP1. Cell Rep 2016; 14 (6): 1382-94.

46. Lu Y, Christian K, Lu B. BDNF: a key regulator for protein synthesis-dependent LTP and long-term memory? Neurobiol Learn Mem 2008; 89 (3): 312-23.

47. Cissé M, Duplan E, Lorivel T, Dunys J, Bauer C, Meckler $\mathrm{X}$, et al. The transcription factor XBP1s restores hippocampal synaptic plasticity and memory by control of the Kalirin-7 pathway in Alzheimer model. Mol Psychiatry 2017; 22 (11): 1562-75.

48. Mandela P, Ma XM. Kalirin, a key player in synapse formation, is implicated in human diseases. Neural Plast. 2012; 2012: 728161.

49. Hetz C, Chevet E, Harding HP. Targeting the unfolded protein response in disease. Nat Rev Drug Discov 2013; 12 (9): 703-19.

50. Boyce M, Bryant KF, Jousse C, Long K, Harding HP, Scheuner D, et al. A selective inhibitor of eIF2alpha dephosphorylation protects cells from ER stress. Science 2005; 307 (5711): 935-9.

51. Mercado G, Hetz C. Drug repurposing to target proteostasis and prevent neurodegeneration: Accelerating translational efforts. Brain 2017; 140: 1544-7.

52. Sidrauski C, Acosta-Alvear D, Khoutorsky A, Vedantham P, Hearn BR, Li H, et al. Pharmacological brake-release of mRNA translation enhances cognitive memory. Elife 2013; 2: e00498.

53. Johnson ECB, J. Kang J. A small molecule targeting protein translation does not rescue spatial learning and memory deficits in the hAPP-J20 mouse model of Alzheimer's disease. Peer J 2016; 4: e2565.

54. Valdés P, Mercado G, Vidal RL, Molina C, Parsons G, Court FA, et al. Control of dopaminergic neuron survival by the unfolded protein response transcription factor XBP1. Proc Natl Acad Sci U S A 2014; 111 (18): 6804-9.

55. Zuleta A, Vidal RL, Armentano D, Parsons G, Hetz C. AAV-mediated delivery of the transcription factor $\mathrm{XBP} 1 \mathrm{~s}$ into the striatum reduces mutant Huntingtin aggregation in a mouse model of Huntington's disease. Biochem Biophys Res Commun 2012; 420 (3): 558-63.

56. Oñate M, Catenaccio A, Martínez G, Armentano D, Parsons $\mathrm{G}$, Kerr B, et al. Activation of the unfolded protein response promotes axonal regeneration after peripheral nerve injury. Sci Rep 2016; 6: 21709.

57. Lindquist SL, Kelly JW. Chemical and biological approaches for adapting proteostasis to ameliorate protein misfolding and aggregation diseases-progress and prog- nosis. Cold Spring Harb Perspect Biol 2011; 3 (12).

58. Ricobaraza A, Cuadrado-Tejedor M, Pérez-Mediavilla A, Frechilla D, Del Río J, García-Osta A. Phenylbutyrate ameliorates cognitive deficit and reduces tau pathology in an Alzheimer's disease mouse model. Neuropsychopharmacology 2009; 34 (7): 1721-32.

59. Dionísio PA, Amaral JD, Ribeiro MF, Lo AC, D'Hooge $\mathrm{R}$, Rodrigues CM. Amyloid- $\beta$ pathology is attenuated by tauroursodeoxycholic acid treatment in APP/PS1 mice after disease onset. Neurobiol Aging 2015; 36 (1): 228-40.

60. Du J, Liang Y, Xu F, Sun B, Wang Z. Trehalose rescues Alzheimer's disease phenotypes in APP/PS1 transgenic mice. J Pharm Pharmacol 2013; 65 (12): 1753-6.

61. Miller JW, Selhub J, Nadeau MR, Thomas CA, Feldman RG, Wolf PA. Effect of L-dopa on plasma homocysteine in PD patients: relationship to B-vitamin status. Neurology 2003; 60 (7): 1125-9.

62. Rogers JD, Sánchez-Saffon A, Frol AB, Diaz-Arrastia R. Elevated plasma homocysteine levels in patients treated with levodopa: association with vascular disease. Arch Neurol 2003; 60 (1): 59-64.

63. Morrison C. Landmark gene therapy poised for US approval. Nat Rev Drug Discov 2017; 16: 739-41.

64. Naldini L. Gene therapy returns to centre stage. Nature 2015; 526 (7573): 351-60.

65. Senior M. After Glybera's withdrawal, what's next for gene therapy? Nat Biotechnol 2017; 35(6): 491-2.

66. Wang D, Gao G. State-of-the-art human gene therapy: part I. Gene delivery technologies. Discov Med 2014; 18 (97): 67-77.

67. Weinberg MS1, Samulski RJ, McCown TJ. Adeno-associated virus (AAV) gene therapy for neurological disease. Neuropharmacology 2013; 69: 82-8.

68. Mingozzi F, High KA. Therapeutic in vivo gene transfer for genetic disease using AAV: progress and challenges. Nat Rev Genet 2011; 12 (5): 341-55.

69. Mendell JR, Al-Zaidy S, Shell R, Arnold WD, Rodino-Klapac LR, Prior TW, et al. Single-Dose Gene-Replacement Therapy for Spinal Muscular Atrophy. N Engl J Med 2017; 377 (18): 1713-22.

70. Loera-Valencia R, Piras A, Ismail MAM, Manchanda S, Eyjolfsdottir H, Saido TC, et al. Targeting Alzheimer's disease with gene and cell therapies. J Intern Med 2018; 284 (1): 2-36.

71. Bourdenx M, Dutheil N, Bezard E, Dehay B. Systemic gene delivery to the central nervous system using Adeno-associated virus. Front Mol Neurosci 2014 J; 7: 50.

72. Gerakis Y, Hetz C. Emerging roles of ER stress in the etiology and pathogenesis of Alzheimer's disease. FEBS J 2018; 285 (6): 995-1011. 